\title{
Adoption of technology applications in healthcare: the influence of attitude toward knowledge sharing on technology acceptance in a hospital
}

\begin{abstract}
The use of different forms of technology has increased in healthcare profession recently. Clinical IT can change the practice patterns of healthcare professionals to improve the quality of health care delivery. When a new clinical IT is introduced in a hospital, healthcare professionals play an important role in the adoption and implementation process. But underutilization of clinical IT has emerged as a new challenge for the healthcare industry. So that healthcare professionals have not fully adopted the clinical IT systems. To improve overall acceptance of clinical IT in a hospital setting, this study (as a conceptual research) argues that unique feature of clinical IT can potentially affect healthcare professionalsô adoption of new clinical IT system. This study proposes a modified technology adoption model (TAM) to incorporate both the special characteristic of healthcare professionals and unique feature of clinical IT. This study discuses that how attitude toward knowledge sharing affects healthcare professionalsôintention to use the clinical IT system.
\end{abstract}

Keyword: Attitude toward knowledge sharing; Clinical IT; Healthcare professionals' involvement in decision making; Perceived ease of use; Perceived threat to professional autonomy; Perceived usefulness; TAM 